\title{
Adaptive Tracking of Atmospheric Releases
}

\author{
D.J. Larson and R. Calhoun
}

January 31, 2002

U.S. Department of Energy

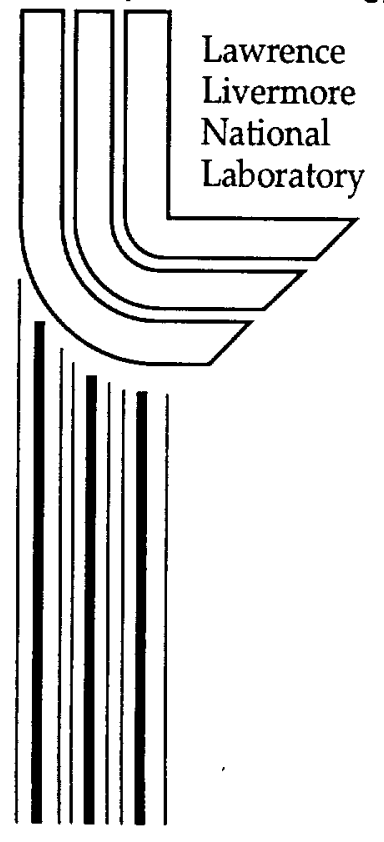

Approved for public release; further dissemination unlimited 


\section{DISCLAIMER}

This document was prepared as an account of work sponsored by an agency of the United States Government. Neither the United States Government nor the University of California nor any of their employees, makes any warranty, express or implied, or assumes any legal liability or responsibility for the accuracy, completeness, or usefulness of any information, apparatus, product, or process disclosed, or represents that its use would not infringe privately owned rights. Reference herein to any specific commercial product, process, or service by trade name, trademark, manufacturer, or otherwise, does not necessarily constitute or imply its endorsement, recommendation, or favoring by the United States Government or the University of California. The views and opinions of authors expressed herein do not necessarily state or reflect those of the United States Government or the University of California, and shall not be used for advertising or product endorsement purposes.

This is a preprint of a paper intended for publication in a journal or proceedings. Since changes may be made before publication, this preprint is made available with the understanding that it will not be cited or reproduced without the permission of the author.

This report has been reproduced directly from the best available copy.

Available electronically at http://www.doc.gov/bridge

Available for a processing fee to U.S. Department of Energy

And its contractors in paper from

U.S. Department of Energy

Office of Scientific and Technical Information

$$
\text { P.O. Box } 62
$$

Oak Ridge, TN 37831-0062

Telephone: (865) 576-8401

Facsimile: (865) 576-5728

E-mail: reports@adonis.osti.gov

Available for the sale to the public from

U.S. Department of Commerce

National Technical Information Service

5285 Port Royal Road

Springfield, VA 22161

Telephone: (800) 553-6847

Facsimile: (703) 605-6900

E-mail: orders@ntis.fedworld.gov

Online ordering: http://www.ntis.gov/ordering.htm

\section{OR}

Lawrence Livermore National Laboratory

Technical Information Department's Digital Library

http://www.llnl.gov/tid/Library.html 


\section{Adaptive Tracking of Atmospheric Releases \\ 01-ERD-092}

D. J. Larson, R. Calhoun

When dangerous chemical or biological releases occur in the atmosphere, emergency responders and decision makers must assess exposure rates to the affected population, establish evacuation routes, and allocate medical resources. We have ber working to improve the scientific basis for making such decisions.

We believe that future rapid response teams, from LLNL and other centers of expertise, will use a variety of atmospheric sensors and atmospheric computer models to predict and characterize the movement of chemical or biological releases in urban environments, and that LLNL is likely to contribute expertise in this area. A key advance will be to merge the information and capabilities of computer models with real-time, atmospheric data from sensors. The resulting product will dynamically interpolate and extrapolate the raw sensor data into a coordinated "picture" or interpretation of the developing flow scenario.

The scientific focus of the project was the exploration and development of algorithms to fuse lidar data (which measure wind speed much as a police radar measures vehicle speed) and a dispersion model into a single system. Our goal was to prowle the scientific foundation for a combined lidar/model approach capable of accurately tracking the evolution of atmospheric releases on distance scales of about $20 \mathrm{~km}$. The fuit tamental idea is to create feedbacks, so that lidar data can be used for wind field irputs into a dispersion model, which would, in turn, guide lidar data acquisition by directing more intensive scanning to regions where more data are key to improving the modeling.

Both of us moved to different career positions during the middle of this first year of the project. One (R. C.) is now at Arizona State University, and the other (D. L.) is with A Division at LLNL. It was therefore necessary to return about half of the grant award to the LDRD committee. Despite this, however, good progress was made on the first half of the project, resulting in three major accomplishments.

We created a database of synthetic lidar data that can be used to test algorithms relating to a combined lidar/dispersion model. We obtained the data, which represent 
nocturnal atmospheric drainage flows in the Salt Lake City Basin, from calculations on the LLNL ASCI White supercomputer with a computational fluid dynamics model running in large-eddy simulation mode. A simple modification of the resulting air-flow data produced radial velocity wind field data (see Figure), which may be directly compared with real lidar data and substituted for them. We have produced a short animation (which can be viewed in the CD-ROM version of this article) representing drainage flow from the mountains. The assumed position of the lidar was that of an actual lidar that took data in the Urban Dispersion Project, funded by DOE, in the fall of 2000.

We studied the "Terminal Winds" project at the Lincoln Laboratory of the Massachusetts Institute of Technology. We analyzed algorithms and approaches used by other scientists on related or relevant projects. We evaluated the Gauss-Markov theorem approach and concluded that it will be useful in designing an advanced sensor integration system for incorporating lidar into numerical models, and, in particular, to build a single interpretation of a flow field based on potentially conflicting sensor data.

We began development of a script-based "test" laboratory, which samples the database and provides input to a dispersion model, which was ported and tested on the Frost computer system at LLNL. Our results demonstrate that specially sampled data from numerical models can indeed be a useful surrogate for actual lidar data which can only be gathered currently at great expense. The further development of the algorithms and ideas relating to this project continue at Arizona State University (ASU) where the PI is now an Assistant Professor of Mechanical and Aerospace Engineering. LLNL and ASU have recently established a collaboration entitled "Advanced Sensor Integration into NARAC's Atmospheric Data Assimilation Program" which we believe will benefit from the groundwork provided by this LDRD. 


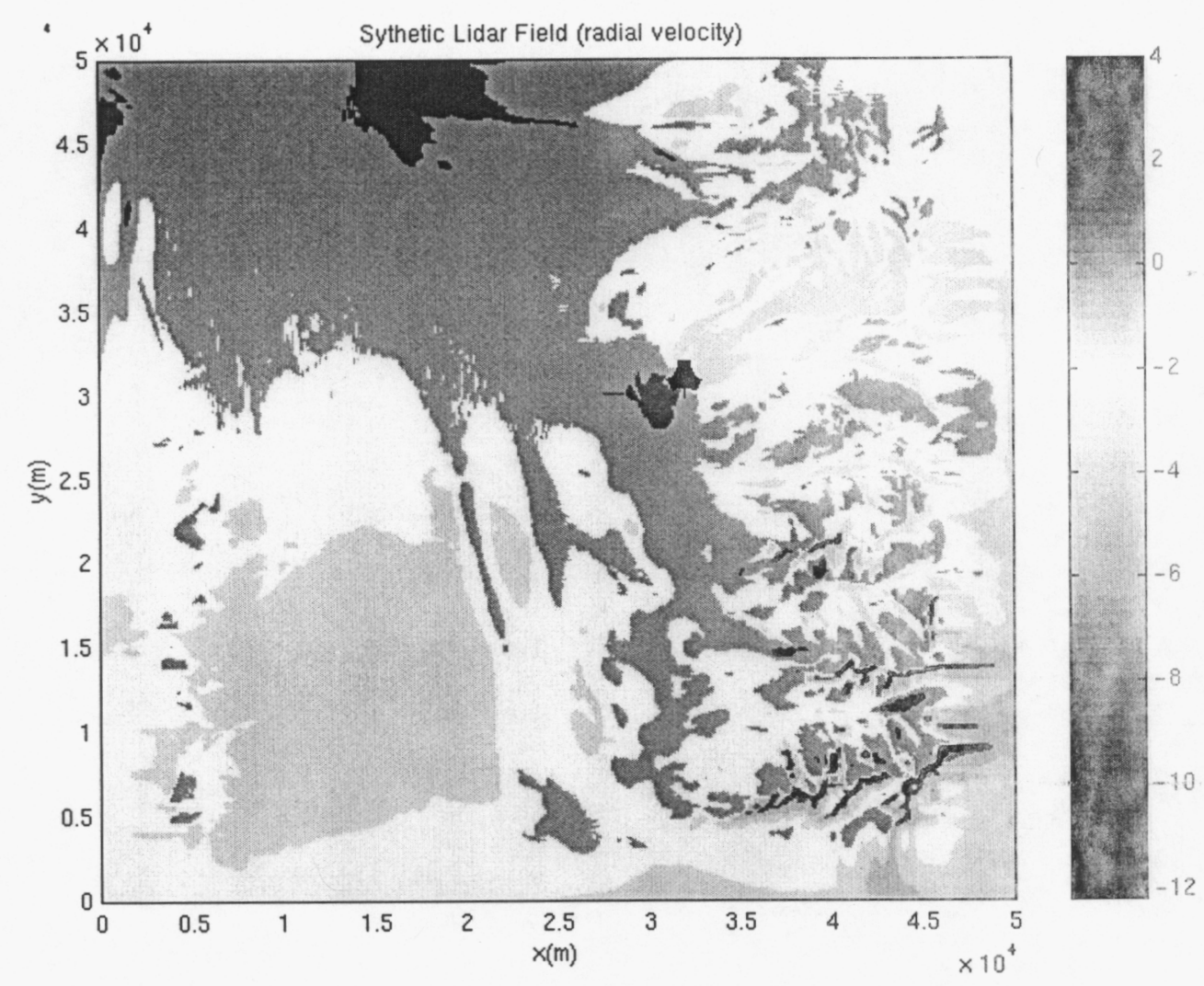

\section{Figure Caption:}

Synthetic lidar data representing night-time drainage airflow from the mountains around

Salt Lake City, Utah, as "seen" by a lidar whose position is indicated by the black symbol. Such synthetic data can be used in developing a combined lidar/computational model to track and predict the course of atmospheric releases.

This work was performed under the auspices of the U.S. Department of Energy by the University of California, Lawrence Livermore National Laboratory under contract No. W-7405-Eng-48. 